OPEN ACCESS

Edited by:

Peter G. Bruce,

University of St. Andrews, UK

Reviewed by:

Jinping Liu,

Wuhan University of Technology,

China

Jie Xiao,

Pacific Northwest National

Laboratory, USA

Shichun Mu,

Wuhan University of Technology,

China

*Correspondence:

Weitao Zheng,

Department of Material Science, Key laboratory of Automobile Materials of

MOE, and State Key Laboratory of

Superhard Materials, Jilin University,

Changchun 130012, P. R. China wtzheng@jlu.edu.cn

Specialty section:

This article was submitted to Energy

Storage, a section of the journal

Frontiers in Energy Research

Received: 03 December 2014

Accepted: 24 April 2015

Published: 08 May 2015

Citation:

Zhao $C$ and Zheng W (2015) A review

for aqueous electrochemical supercapacitors.

Front. Energy Res. 3:23.

doi: 10.3389/fenrg.2015.00023

\section{A review for aqueous electrochemical supercapacitors}

\author{
Cuimei Zhao ${ }^{1}$ and Weitao Zheng ${ }^{2 *}$ \\ ${ }^{1}$ Key Laboratory of Preparation and Applications of Environmental Friendly Materials, Ministry of Education, College of \\ Chemistry, Jilin Normal University, Siping, China, ${ }^{2}$ Department of Materials Science, Key Laboratory of Mobile Materials, \\ Ministry of Education and State Key Laboratory of Superhard Materials, Jilin University, Changchun, China
}

Electrochemical capacitor is the most promising energy-storage device that can meet the demands of high-power supply and long cycle life; however, low-energy density and highfabrication cost limit its further development. Researchers have paid more attention to the development of electrode material in the past, and very few people attach importance to the research of the electrolyte, especially the redox electrolyte, which is important for improving specific capacitance greatly. This paper presents a review of the research in not only electrode material but also redox aqueous electrolyte and together with an important part of supercapacitor device. The advantages and disadvantages for different electrode material and electrolyte are discussed. And the new trends in supercapacitor development are also summarized.

Keywords: electrode, electrolyte, additive, supercapacitor, energy density, power density, cycling stability

\section{Introduction}

Energy is an important issue all over the world. The rapid deterioration of environment and depletion of fossil fuels call not only for more clean and renewable energy sources but also more advanced energy conversion/storage systems. Research efforts have mostly focused on two types of electrochemical devices: batteries and capacitors. As shown in Figure 1 (Simon and Gogotsi, 2008), batteries suffer from low-power density although they have high-energy density, whereas conventional capacitors exhibit high power but low-energy density. Supercapacitor, also known as an electrochemical capacitor (EC), has bridged the gap between battery and conventional capacitor, because of the great advantages including high power and energy supply, long cycle life, flexible operating temperature, and environmental friendliness (Conway, 1999; Burke, 2000, 2010; Frackowiak and Beguin, 2001; Pandolfo and Hollenkamp, 2006; Frackowiak, 2007; Zhang and Chen, 2008; Zhang and Zhao, 2009; Conte, 2010; Inagaki et al., 2010; Zhai et al., 2011; Chen et al., 2013a; Zhi et al., 2013). ECs are widely used in consumer electronics, hybrid vehicles, and industrial power/energy managements. However, the disadvantages of low-energy density and highfabrication cost for ECs have been identified as a major challenge for the capacitive storage science. To meet the energy demands for practical applications, advanced supercapacitors must be developed with high-energy density without sacrificing the power density and cycle life. The energy density (E) can be obtained by the total capacitance $(\mathrm{C})$ and the cell voltage $(\mathrm{V})$ based on Eq. 1:

$$
\mathrm{E}=1 / 2 \mathrm{CV}^{2}
$$

Therefore, there have already appeared two methods in increasing energy density. First, to improve the total capacitance, the most intensive approaches include the discovery of advanced electrode materials and the improved understanding of ion transport mechanism 


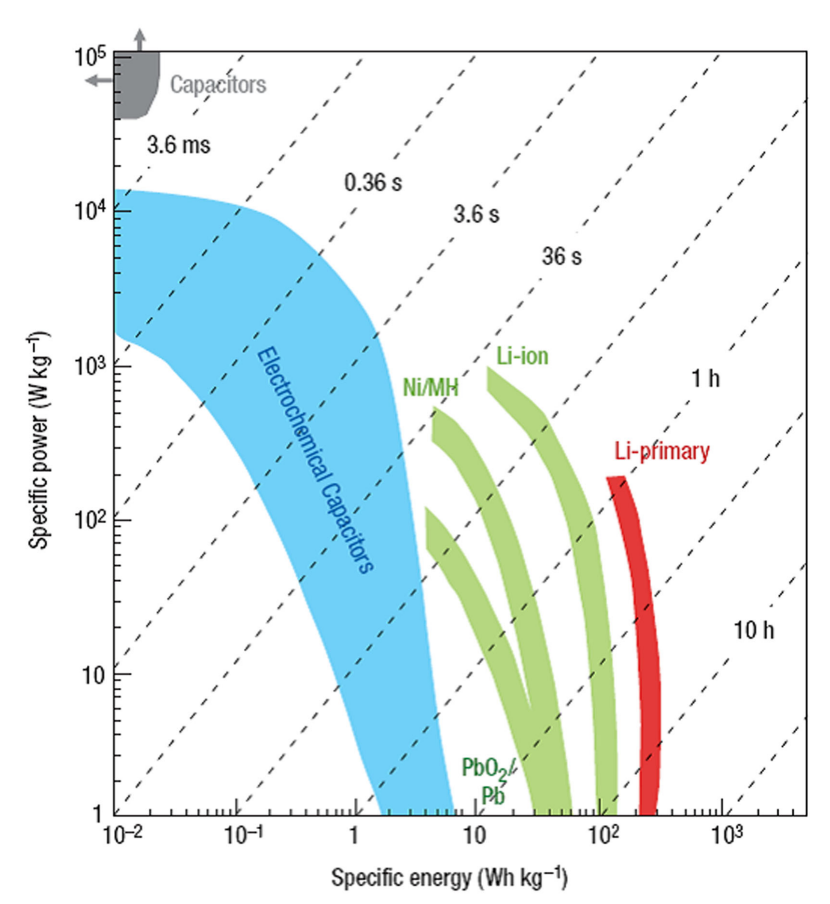

FIGURE 1 | Specific power against specific energy, also called a Ragone plot, for various electrical energy-storage devices. The shaded curves were obtained from Simon and Gogotsi (2008).

in small pores (Zhai et al., 2011); however, the improvement in total capacitance is not significant only by electrode materials. Very recently, there have been a few reports that redox additives are introduced into the conventional electrolyte, with additional pseudocapacitive attribution of the additives between the electrode and electrolyte, the capacitance is obviously enhanced ( $\mathrm{Su}$ et al., 2009; Roldán et al., 2011; Wu et al., 2012; Chen et al., 2013b; Senthilkumar et al., 2013). Second, to improve the cell voltage, asymmetric supercapacitors combining electric doublelayer anode and redox reaction cathode show promising capacitive performance.

\section{Electrode Materials}

In principle, capacitive behavior can be classified into two types: the electrical double-layer capacitance (EDLC) arising from electrostatic attraction between electrolyte and electrode surface; the pseudocapacitance associated with fast and reversible faradic reactions of the active species on the surface of the electrode (Zhang and Zhao, 2009; Zhai et al., 2011). Therefore, according to the fundamental energy-storage mechanisms, the typical electrode material is EDLC material, such as various carbon materials. The other is pseudocapacitance material based on transition-metal oxides/hydroxides and conducting polymer. Besides, MXenes and MOF material are the latest electrode material.

\section{Carbon Materials}

Carbon materials, corresponding to EDLC, are considered the most ideal materials for ECs for high-specific surface area, good electronic conductivity, excellent chemical stability, easy processing, lower cost, and wide operating temperature range (Zhang et al., 2009a). A variety of carbon materials are involved, such as activated carbon (AC) (Ricketts and Ton-That, 2000; Pognon et al., 2012), carbon aerogels (Saliger et al., 1998; Wei et al., 2005), carbon nanotubes (CNTs), carbon nanofibres (An et al., 2001; Zhang et al., 2009b), and so on. Conventional AC, with a theoretical capacitance of $100 \sim 300 \mathrm{Fg}^{-1}$, exhibits an excellent cycling stability in several electrolytes. Recently, graphene nanosheets, two-dimensional layers of $\mathrm{sp}^{2}$-bonded carbon, have been found to be an ideal carbon electrode material for ECs (Stoller et al., 2008; Zhao et al., 2009a; Zhu et al., 2010; Le et al., 2011), with an ideal capacitance of $550 \mathrm{Fg}^{-1}$ when the specific surface area of $2675 \mathrm{~m}^{2} \mathrm{~g}^{-1}$ is fully used (Liu et al., 2010).

A lot of research has been done for various carbon materials at home and abroad, but the study was only limited to improving the pore size distribution, surface area, and surface functional groups of the carbon material. However, the specific capacitance cannot be improved significantly because of double-layer capacitance mechanisms. At present, the combination of carbon material and pseudocapacitive material can bring synergistic effect, realizing the overall system excellent electrochemical performance.

\section{Metal Oxides/Hydroxides}

Based on the faradic pseudocapacitive energy-storage mechanism, metal oxides/hydroxides, such as ruthenium, manganese, cobalt, nickel, and vanadium, can provide higher specific capacitance than conventional carbon materials and better cycling stability than polymer materials.

Ruthenium oxide, with wide potential window, high-redox reversibility and high conductivity shows remarkably high-energy density, power density, and cycling stability (Sakiyama et al., 1993; Jia et al., 1996; Kim and Kim, 2006; Lee et al., 2010). For example, the capacitance can be as high as $1300 \mathrm{Fg}^{-1}$ for nanotubular arrayed electrode of hydrous ruthenium oxide (Hu et al., 2006). However, the high cost for precious metal becomes a major barrier for the commercialization. The present study mainly concentrated in two aspects: first, composite ruthenium oxide with carbon or cheap metal oxide material, to improve the utilization ratio of ruthenium oxide; second, seek cheap metal oxide/hydroxide to replace precious metals (Zheng and Jow, 1996; Fang et al., 2001; Hu and Huang, 2001; Jeong and Manthiram, 2001; Ke et al., 2005; Zhao et al., 2012a; Sellam and Hashmi, 2013). For example, Zhang et al. (2014) have reported a facile hydrothermal method without reducer to fabricate graphene- $\mathrm{RuO}_{2}$ nanocomposites, achieving high-specific capacitance in alkaline/acidic/neutral electrolyte. Wang and Zhang (2004) have designed to load $\mathrm{Ru}_{1-y} \mathrm{Cr}_{\mathrm{y}} \mathrm{O}_{2}$ on the $\mathrm{TiO}_{2}$ nanotubes with a maximum specific capacitance of $1272.5 \mathrm{~F} \mathrm{~g}^{-1}$ obtained. Partially due to the discovery of advanced electrode materials and new synthetic method, more and more electrode materials with high performance have been developed (Simon and Burke, 2008; Simon and Gogotsi, 2008). In recent years, inexpensive pseudocapacitive active materials, such as $\mathrm{Co}_{3} \mathrm{O}_{4} / \mathrm{Co}(\mathrm{OH})_{2}$ (Simon and Burke, 2008; Wang et al., 2009; Gao et al., 2010; Xu et al., 2010; Yuan et al., 2010, 2012; Anantharamulu et al., 2011; Asano et al., 2011; Xia et al., 2011a; Huang et al., 2012), $\mathrm{NiO}_{4} / \mathrm{Ni}(\mathrm{OH})_{2}$ (Song and Gao, 2008; Yuan et al., 2009, 
2011; Zhang et al., 2010; Cao et al., 2011; Jiang et al., 2011; Xia et al., 2011b; Zhu et al., 2012), $\mathrm{MnO}_{\mathbf{x}}$ (Ragupathy et al., 2009; Yan et al., 2010a; Wang et al., 2011; Yu et al., 2011a,b; Lee et al., 2012a, 2013; Song et al., 2012; Si et al., 2013), $\mathrm{Fe}_{3} \mathrm{O}_{4}$ (Obradovic et al., 2009; Zhao et al., 2009b; Lee et al., 2012b), and so on have attracted the attentions of the researchers. Chang et al. (2010) created nanostructure $\mathrm{Co}(\mathrm{OH})_{2}$ electrode, exhibiting a high pseudocapacitance of $2800 \mathrm{~F} \mathrm{~g}^{-1}$ and an outstanding rate capability and cyclic stability. Wang et al. have reported a facile synthesis of nickel cobalt layered double hydroxides (LDHs) on conducting $\mathrm{Zn}_{2} \mathrm{SnO}_{4}$ by CVD and electrochemical deposition. This novel material demonstrates an outstanding electrochemical performance with a highspecific capacitance of $1805 \mathrm{Fg}^{-1}$ at $0.5 \mathrm{Ag}^{-1}$, and an excellent rate performance of $1275 \mathrm{~F} \mathrm{~g}^{-1}$ at $100 \mathrm{~A} \mathrm{~g}^{-1}$ (Wang et al., 2012a). Zhao et al. (2011) have prepared layered $\mathrm{Co}(\mathrm{OH})_{2}$, showing a high-specific capacitance of $651 \mathrm{Fg}^{-1}$, but only $76 \%$ of initial capacitance remains after 500 cycles at $50 \mathrm{mV} \mathrm{s}^{-1}$. With higher specific capacitance, the cycling stability of the pseudocapacitive materials has been sacrificed. This drawback must be overcome (Simon and Gogotsi, 2008). To improve low conductivity and poor stability, such inexpensive pseudocapacitive materials are often incorporated into highly conductive nanostructured materials. Recently, composite electrode material has been studied for ECs, showing good electrochemical performance than that of pure oxide/hydroxide. For example, a facile strategy is designed to deposit $\mathrm{Co}(\mathrm{OH})_{2}$ nanoparticles on graphene sheets in a water-isopropyl alcohol system. The specific capacitance of the grapheme/Co $(\mathrm{OH})_{2}$ nanocomposite reaches $972.5 \mathrm{~F} \mathrm{~g}^{-1}$, leading to a significant improvement compared to each individual counterpart (Chen et al., 2010). Yan et al. (2010b) have composited graphene and $\mathrm{Co}_{3} \mathrm{O}_{4}$, exhibiting a high cycle stability $(95.6 \%$ specific capacitance is retained after 2000 cycles); however, the specific capacitance is only $243.2 \mathrm{Fg}^{-1}$. Unfortunately, most of the reported oxide/graphene materials have been prepared by chemical precipitation method, there exist some problems, the particles are agglomerated easily and a binder is often required, that could decrease the active surface area and increase the internal resistance of the ECs. To overcome the disadvantages, we have focused on binder-free $\mathrm{Ni}(\mathrm{OH})_{2}$ /graphene/Ni foam (Wang et al., 2012 b) or $\mathrm{Co}(\mathrm{OH})_{2}$ /graphene/Ni foam (Zhao et al., 2012b) electrode prepared by a combination of PECVD and electrodeposition method, which could be explored as a promising material for ECs because of high-electrochemical activity and cycle stability. From the discharge curves of Figures $\mathbf{2 A}, \mathbf{B}$, the $\mathrm{Ni}(\mathrm{OH})_{2} /$ graphene/Ni foam electrode maintains $93.3 \%$ of the initial specific capacitance after 500 cycles at a high-current density of $60 \mathrm{~A} \mathrm{~g}^{-1}$, while under the same conditions only $54 \%$ specific capacitance retains for the $\mathrm{Ni}(\mathrm{OH})_{2} / \mathrm{Ni}$ foam electrode, which shows the obvious improvement of cycling stability for the composite electrode (Wang et al., $2012 b)$. In addition, a highly porous $\mathrm{Co}(\mathrm{OH})_{2} /$ graphene film on $\mathrm{Ni}$ foam has been obtained, as shown in Figure 3. The corresponding electrochemical measurement technology also confirmed that the introduction of graphene between $\mathrm{Co}(\mathrm{OH})_{2}$ and $\mathrm{Ni}$ foam demonstrates an obvious enhancement of electrochemical stability compared with $\mathrm{Co}(\mathrm{OH})_{2} / \mathrm{Ni}$ foam (Zhao et al., 2012b). The excellent pseudocapacitive behavior can be explained to the following (Wang et al., 2012b; Zhao et al., 2012b): (1) graphene can provide high-electrical conductivity and high-specific surface
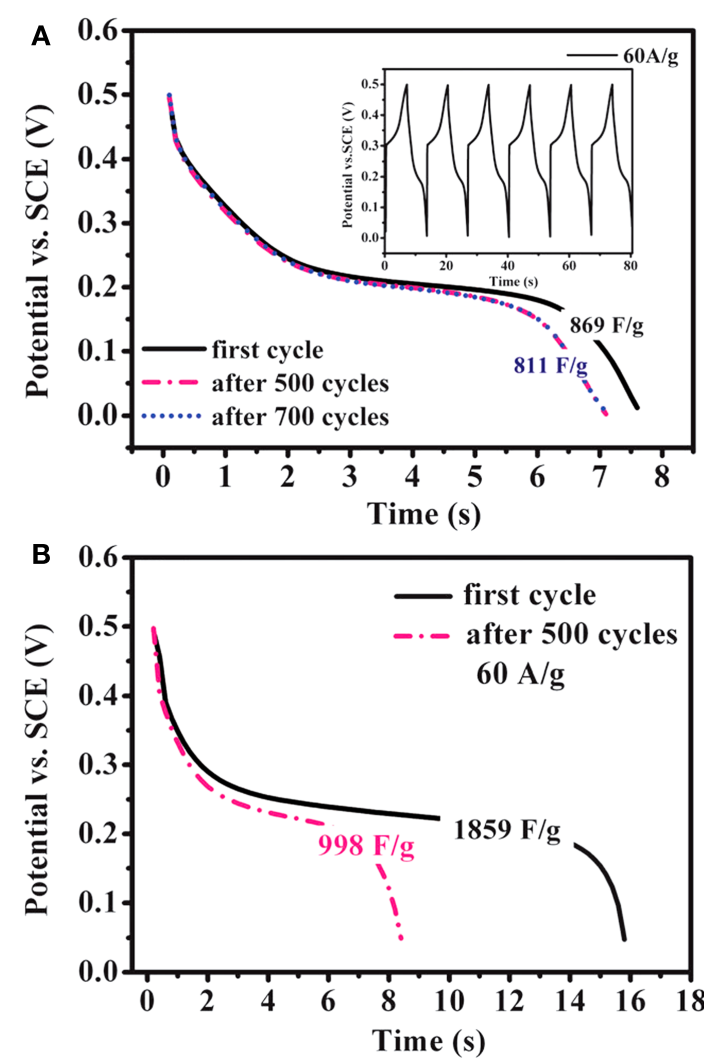

FIGURE 2 | Discharge curves of (A) the Ni foam/graphite nanosheets $/ \mathrm{Ni}(\mathrm{OH})_{2}$ electrode at the current density of $60 \mathrm{Ag}^{-1}$ for 700 cycles and $(B)$ the $\mathrm{Ni}$ foam $/ \mathrm{Ni}(\mathrm{OH})_{2}$ electrode at the same current density for $\mathbf{5 0 0}$ cycles. The inset in (A) shows the charge-discharge curves of the composite electrode. The curves were obtained from Wang et al. (2012b).

area, allowing rapid and effective ion charge transfer; $(2) \mathrm{Ni}(\mathrm{OH})_{2}$ or $\mathrm{Co}(\mathrm{OH})_{2}$ nanosheets with high-electrochemical activity are directly grown on graphene, with the covalent chemical bonding (C-O-Co or C-O-Ni) formed, favoring the electrochemical stability; (3) graphene has been directly deposited on the Ni-foam collector, can avoid increasing the contact resistance between the electrode and the collector. In order to further improve capacitive properties, the effects of crystallinity and electroconductivity of carbon nanomaterials on $\mathrm{Co}(\mathrm{OH})_{2}$ are explored (Zhao et al., 2013a). As shown in Figure 4, the $\mathrm{Co}(\mathrm{OH})_{2}$ nanosheet has been electrochemically deposited on graphene nanosheets (GNS) or amorphous carbon (APC). The electrochemical test results are listed in Table 1, $\mathrm{Co}(\mathrm{OH})_{2} / \mathrm{GNS}$ exhibits a high cycling stability, which is due to that the GNS with high conductivity and excellent flexibility can transfer smooth electrons and accommodate the volume expansion/contraction for $\mathrm{Co}(\mathrm{OH})_{2}$ in the charge-discharge process. By contrast, $\mathrm{Co}(\mathrm{OH})_{2} / \mathrm{APC}$ shows a high-specific capacitance, which can be ascribed to the lower conductivity for APC, leading to the larger nanosheets of $\mathrm{Co}(\mathrm{OH})_{2}$, promoting the complete redox reaction of $\mathrm{Co}(\mathrm{OH})_{2}$ (Zhao et al., 2013a). The carbonaceous supports can not only act as a template to direct the growth of the as-deposited hydroxide but also affect the conductivity of the whole electrode, which may provide a 


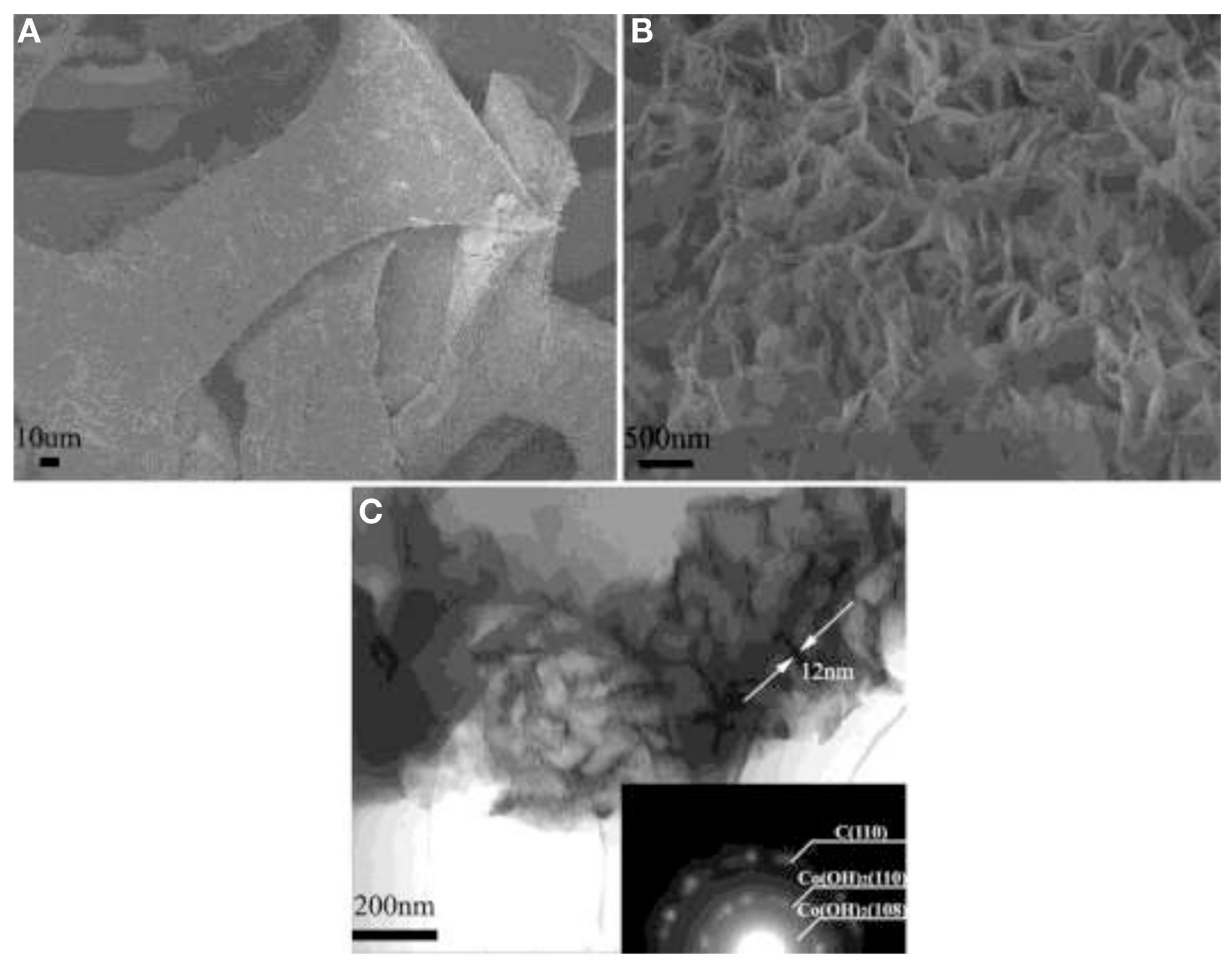

FIGURE 3 | (A,B) SEM images for $\mathrm{Co}(\mathrm{OH})_{2} / \mathrm{GNS}$ on Ni foam and (C) TEM images for $\mathrm{Co}(\mathrm{OH})_{2} / \mathrm{GNS}$. Obtained from Zhao et al. (2012b).

technical reference for improvement in the pseudocapacitance behaviors and controllable preparation of composite electrode material in the future. Besides hybrid metal oxide with carbon material, a novel hybrid metal oxide core/shell nanowire arrays for ECs has been constructed. For example, Liu et al. choose $\mathrm{MnO}_{2}$ and $\mathrm{Co}_{3} \mathrm{O}_{4}$ as the shell and core materials, respectively. The hybrid nanowire array exhibit a high capacitance $\left(480 \mathrm{~F} \mathrm{~g}^{-1}\right.$ at $2.67 \mathrm{~A} \mathrm{~g}^{-1}$ ) and good cycle performance ( $97.3 \%$ capacitance retention after 5000 cycles), which is $4 \sim 10$-fold increase respect to pristine $\mathrm{Co}_{3} \mathrm{O}_{4}$ array. With this electrode design method, the functions of each pseudocapacitive constituent are effectively utilized, and realize a synergistic effect. Growing from the $\mathrm{Co}_{3} \mathrm{O}_{4}$ nanowire scaffold directly, the surfaces of $\mathrm{MnO}_{2}$ nanosheets are well separated, making active material fully available to the $\mathrm{Li}^{+}$in the electrolyte. As ultrathin $\mathrm{MnO}_{2}$ nanosheets construct a highly porous structure on $\mathrm{Co}_{3} \mathrm{O}_{4}$ nanowire, the $\mathrm{Co}_{3} \mathrm{O}_{4}$ core nanowires can be accessed by $\mathrm{OH}^{-}$and initiate the redox reaction (Liu et al., 2011). The concept opens up the possibility of constructing high-performance pseudocapacitive materials without using any carbon-based or conducting media.

\section{Conducting Polymers}

Conducting polymers can provide capacitance behavior through the faradic process. When oxidation takes place, ions are transferred to the polymer backbone, and when reduction occurs, the ions are released from this backbone into the electrolyte (Sharma and Bhatti, 2010). Conducting polymers widely used in supercapacitor mainly contain polyaniline (PANI), polythiophene (PTh), polypyrrol (PPy), and their corresponding derivatives, due to its advantageous properties of low cost, high-voltage window, and high-doping rate during charge-discharge process. However, high resistance and low stability limit the wide application. Especially, swelling and shrinkage may occur during charge-discharge processes, leading to mechanical degradation of the electrodes and fading of the capacitive performance.

Fabricating composite electrode materials to improve the conductivity and stability become the new development direction. For example, a high-performance polyaniline electrode has been prepared by electrochemical deposition on a porous carbon monolith, showing the advancement of high-specific capacitance, excellent rate capability, and good cycling stability. A capacitance value as high as $2200 \mathrm{Fg}^{-1}$ is obtained at a current density of $0.67 \mathrm{~A} \mathrm{~g}^{-1}$, and the specific capacitance is still up to $1270 \mathrm{~F} \mathrm{~g}^{-1}$ even at the high-current density of $66.7 \mathrm{Ag}^{-1}$ (Fan et al., 2007). Tao et al. (2014) have developed $\mathrm{PPy} / \mathrm{MnO}_{2}$ composite through a simple electrodeposition process. The highest areal capacitance of the $\mathrm{PPy} / \mathrm{MnO}_{2}$ electrode is about $2.45 \mathrm{~F} \mathrm{~cm}^{-2}$ at a current density of $0.2 \mathrm{~mA} \mathrm{~cm}^{-2}$, and the capacity retention is $98.6 \%$ after 1000 cycles.

\section{Latest Electrode Materials}

Recently, MXenes have been prepared combining hydrophilic surfaces with good conductivities. MXenes are synthesized by the extraction of the "A" layers from the layered carbides or carbonitrides known as MAX phases. MXenes show promise as electrode materials for Li-ion batteries and Li-ion capacitors; however, many are theoretically predicted (Khazaei et al., 2012; 

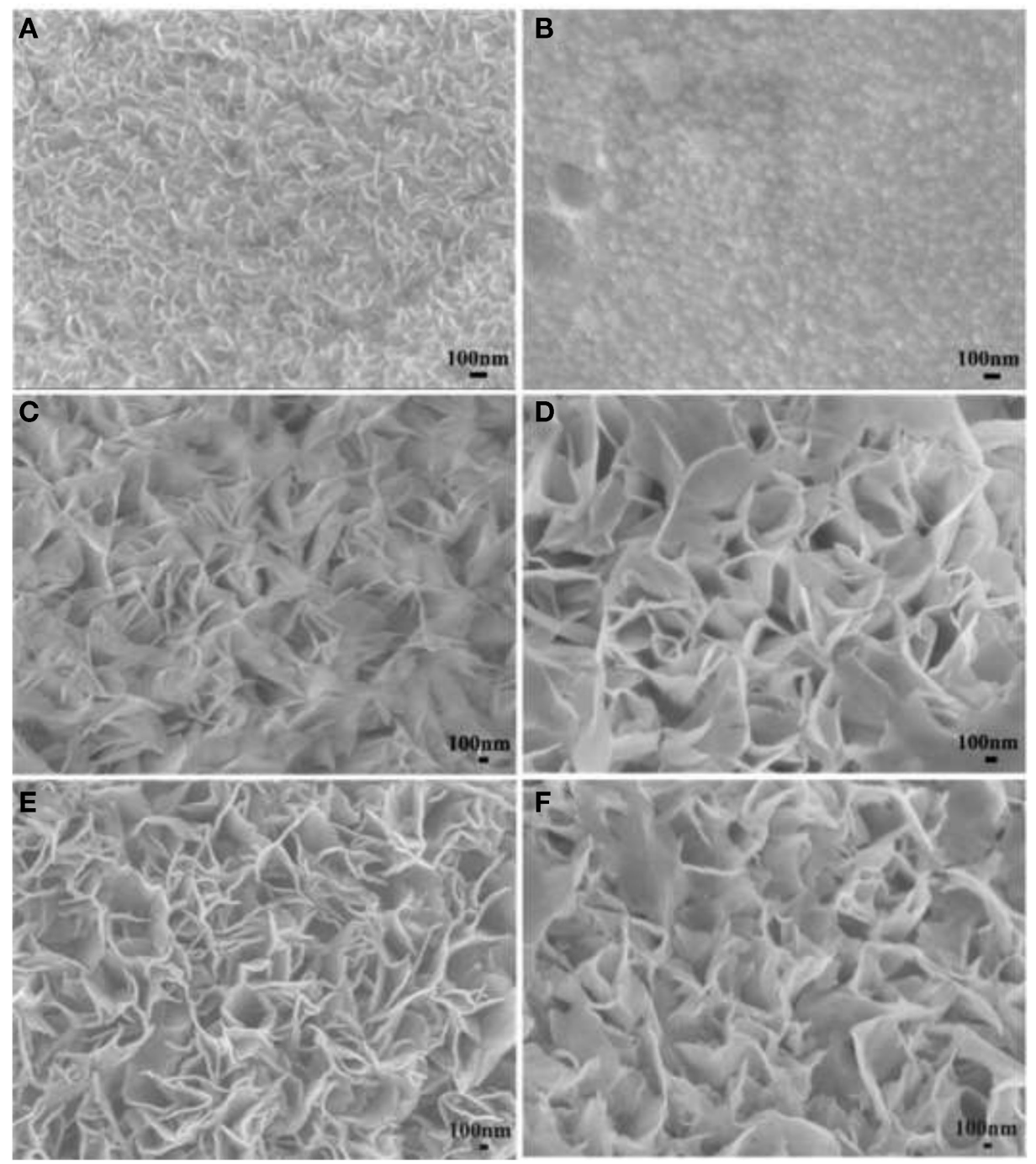

FIGURE 4 | SEM images for (A) GNS, (B) APC, (C) $\mathrm{Co}(\mathrm{OH})_{2} / \mathrm{GNS}$, and (D) $\mathrm{Co}(\mathrm{OH})_{2} / \mathrm{APC}$ before discharge/charge cycles; (E) $\mathrm{Co}(\mathrm{OH})_{2} / \mathrm{GNS}$ and (F) $\mathrm{Co}(\mathrm{OH})_{2} / \mathrm{APC}$ after 2000 discharge/charge cycles. Obtained from Zhao et al. (2013a).

Kurtoglu et al., 2012). Maria et al. have reported an intercalationinduced high capacitances of $\mathrm{Ti}_{3} \mathrm{C}_{2} \mathrm{~T}_{\mathrm{x}}$ paper electrodes in aqueous electrolytes $(\mathrm{KOH}$ or $\mathrm{NaOH}), 350 \mathrm{~F} \mathrm{~cm}^{-1}$ at $1 \mathrm{~A} \mathrm{~g}^{-1}$ and $60 \%$ rate capability from 2 to $100 \mathrm{mV} \mathrm{s}^{-1}$ achieved (Lukatskaya et al., 2013). $\mathrm{The} \mathrm{Ti}_{3} \mathrm{C}_{2} \mathrm{~T}_{\mathrm{x}}$ material opens the door for the use of MXenes in energy-storage devices. As noted, the reported capacitances are probably far from the maximum values possible for MXenes in general. A variety of ions should be accommodated between the MXene layers.

Compared to inorganic high-surface-area materials, MOFs offer the theoretical advantage of $100 \%$ utilization and improved accessibility of the metal-cation centers due to their regular 3D dispersion in an openstructure. For example, the introduction of MOFs in EDLCs has been reported only recently (Diaz et al., 2012; Lee et al., 2012c). Lee et al. have synthesized a Co-based MOF from cobalt nitrate and terephthalic acid, and the capacitive behavior was investigated in various $1 \mathrm{M}$ aqueous electrolytes $(\mathrm{LiOH}, \mathrm{KCl}$,
$\mathrm{LiCl}$, and $\mathrm{KOH})$. Only in $\mathrm{LiOH}$ electrolyte, did the Co-based $\mathrm{MOF}$ shows an interesting pseudocapacitive behavior with a specific capacitance of $150 \sim 200 \mathrm{Fg}^{-1}$ and $98.5 \%$ capacitance retention after 1000 cycles. However, to date, it is difficult to find that MOFs electrode materials is clear advantaged in performance, durability, or cost compared to other materials. For real breakthroughs, MOFs will probably need to be designed and optimized, with controlling the MOF particle size, improving conductive character, and so on.

\section{Electrolyte}

Besides two electrodes, electrolyte plays an important role in capacitor performance, such as ion supplementary, electric charge conduction, and electrode particles adhesive. The requirements for an electrolyte in ES include wide voltage window, highelectrochemical stability, low resistivity, low toxicity, and so on. 
TABLE 1 | Electrochemical properties of $\mathrm{Co}(\mathrm{OH})_{2} / \mathrm{GNS}, \mathrm{Co}(\mathrm{OH})_{2} / \mathrm{APC}$ and $\mathrm{Co}(\mathrm{OH})_{2} /$ GNS-APC.

\begin{tabular}{|c|c|c|c|}
\hline Active mass & $\mathrm{Co}(\mathrm{OH})_{2} / \mathrm{GNS}$ & $\mathrm{Co}(\mathrm{OH})_{2} / \mathrm{APC}$ & $\begin{array}{l}\mathrm{Co}(\mathrm{OH})_{2} / \\
\text { GNS-APC }\end{array}$ \\
\hline \multicolumn{4}{|l|}{ Current density } \\
\hline $2 \mathrm{Ag}^{-1}$ & 692.0 $\mathrm{Fg}^{-1}$ & $1287.2 \mathrm{Fg} \mathrm{g}^{-1}$ & 784.0 $\mathrm{Fg}^{-1}$ \\
\hline $4 \mathrm{Ag}^{-1}$ & $653.1 \mathrm{Fg}^{-1}$ & $1194.9 \mathrm{Fg}^{-1}$ & $754.9 \mathrm{Fg}^{-1}$ \\
\hline $8 \mathrm{Ag}^{-1}$ & $610.9 \mathrm{Fg}^{-1}$ & $1051.6 \mathrm{Fg}^{-1}$ & $724.4 \mathrm{Fg}^{-1}$ \\
\hline $16 \mathrm{Ag}^{-1}$ & $567.3 \mathrm{Fg}^{-1}$ & $904.7 \mathrm{Fg}^{-1}$ & $692.4 \mathrm{Fg}^{-1}$ \\
\hline $32 \mathrm{Ag}^{-1}$ & $517.8 \mathrm{Fg}^{-1}$ & $762.2 \mathrm{Fg}^{-1}$ & $651.6 \mathrm{Fg}^{-1}$ \\
\hline $\begin{array}{l}\text { Maintained capacitance } \\
2 \sim 32 \mathrm{Ag}^{-1}\end{array}$ & $74.8 \%$ & $59.2 \%$ & $83.1 \%$ \\
\hline $\begin{array}{l}\text { capacitance after } 2000 \mathrm{cp} \\
\text { at } 40 \mathrm{Ag}^{-1}\end{array}$ & $95.7 \%$ & $83.8 \%$ & $93.2 \%$ \\
\hline
\end{tabular}

Bold are the best pseudocapacitive properties including cycling stability, specific capacitance, and rate capability among the three materials, further confirmed that different carbon nanomaterials have different influences on the electrochemical properties of $\mathrm{Co}(\mathrm{OH})_{2}$.

This table was obtained from Zhao et al. (2013a).

The electrolyte used in ECs manly includes aqueous electrolyte, organic electrolyte.

\section{Aqueous Electrolytes}

As far as the electrolytes are considered, aqueous electrolytes (such as $\mathrm{KOH}, \mathrm{H}_{2} \mathrm{SO}_{4}, \mathrm{Na}_{2} \mathrm{SO}_{4}$ aqueous solution, and so on) have the advantages of high-ionic conductivity, low cost, non-flammability, non-corrosiveness, safety, and convenient assembly in air, compared to organic electrolytes, which are believed to be less conductive, expensive, usually flammable, and higher toxic. However, the potential window $(\sim 1.2 \mathrm{~V})$ for aqueous electrolytes is far lower than that of organic electrolyte. According to Eq. 1, low-potential window is the reason of low-energy density that limits its market application. The introduction of redox active substance in aqueous electrolytes can effectively enhance the capacitance via extra redox reaction between the electrode and electrolyte, which is shown in the part of symmetric supercapacitors.

\section{Organic Electrolyte}

The restriction of aqueous electrolytes is the limited operating voltage (about $1.2 \mathrm{~V}$ ). By contrast, organic electrolytes can provide a high-operating voltage up to $4 \mathrm{~V}$. High-potential window is a large advantage for organic electrolyte. Among organic electrolytes solvents, acetonitrile (AN) and propylene carbonate (PC) are the most common. Besides, organic salts such as tetraethylammonium tetrafluoroborate and tetraethylphosphonium tetrafluoroborate have also been used in ECs electrolytes. However, there exist the following problems for organic electrolyte: first, high resistance limits the power density of capacitor; second, high water content limits the working voltage of capacitor.

\section{Supercapacitor}

\section{Symmetric Supercapacitors}

Symmetric supercapacitors with positive and negative electrode material identical or similar can be divided into electric doublelayer capacitor and faradic capacitors according to electrode material working mechanism. Symmetric supercapacitors are mainly carbon//carbon, $\mathrm{Ru} / / \mathrm{Ru}$, and cheap metal symmetric supercapacitor.

Electric double-layer capacitor contains carbon material with high-surface area as the electrode material in aqueous or organic electrolytes. Compared to organic electrolytes, aqueous electrolyte is believed to high-ionic conductivity, low cost, and convenient assembly of ECs in air. However, EDLCs only utilize the electrostatic charge at the electrolyte-electrode surface to store electric energy so that the capacitance is limited. Very recently, an effective approach has been reported wherein redox additives are introduced into the conventional electrolyte to enhance the capacitance via extra redox reaction between the electrode and electrolyte. Yu et al. (2012) have doped m-phenylenediamine into a conventional $\mathrm{KOH}$ electrolyte for carbon-based ECs. The specific capacitance of the supercapacitor based on the new electrolyte is $78.01 \mathrm{~F} \mathrm{~g}^{-1}$, showing an increase of $114.16 \%$ over that of a supercapacitor based on a conventional $\mathrm{KOH}$ electrolyte. Similarly, Roldán et al. (2011) have reported that via adding electrochemically active compound quinone/hydroquinone (Q/HQ) into the $\mathrm{H}_{2} \mathrm{SO}_{4}$ electrolyte, an ultrahigh specific capacitance of $5017 \mathrm{~F} \mathrm{~g}^{-1}$ achieved for carbon-based EC. The significantly improved capacitance attributes to that the faradaic reactions of the Q/HQ couples (HQ $\left.\stackrel{2 \mathrm{H}^{+} 2 \mathrm{e}^{-}}{\longleftrightarrow} \mathrm{Q}\right)$ contribute pseudocapacitance to the electrode. However, working condition is not easily maintained, leading to a poor electrochemical stability. Senthilkumar et al. (2013) have improved the capacitance for $\mathrm{AC}$ materials through adding either $\mathrm{KI}$ or $\mathrm{KBr}$ into $1 \mathrm{M} \mathrm{H}_{2} \mathrm{SO}_{4}$ or $\mathrm{Na}_{2} \mathrm{SO}_{4}$ electrolyte. With an improved specific capacitance, there is also a problem with the electrochemical stability for only relying on the pseudocapacitive contribution from additive for EDLCs.

Although more attention has been paid to investigating redox electrolyte for enhancing the EDLCs, no any efforts have been done to improve pseudocapacitors. We have aimed at improving the pseudocapacitive behavior of $\mathrm{Co}(\mathrm{OH})_{2} / \mathrm{GNS}$ electrode through adding $\mathrm{K}_{3} \mathrm{Fe}(\mathrm{CN})_{6}$ into $\mathrm{KOH}$ electrolyte, in our $\mathrm{CV}$ test result, two symmetric anodic/cathodic pairs are superimposed on a broad redox background, corresponding to the redox reaction of $\mathrm{Co}(\mathrm{OH})_{2}$ electrode and $\mathrm{K}_{3} \mathrm{Fe}(\mathrm{CN})_{6}$ electrolyte, respectively, indicating that reversible redox reactions of $\mathrm{Co}(\mathrm{OH})_{2}$ solid electrode and $\mathrm{K}_{3} \mathrm{Fe}(\mathrm{CN})_{6}$ liquid electrolyte occur simultaneously and independently (Zhao et al., 2013b). The cycling stability for $\mathrm{Co}(\mathrm{OH})_{2} / \mathrm{GNS}$ electrode either in $\mathrm{KOH}$ electrolyte or $\mathrm{K}_{3} \mathrm{Fe}(\mathrm{CN})_{6}+\mathrm{KOH}$ electrolyte is examined by charge-discharge tests for 2000 cycles at a high current density of $80 \mathrm{Ag}^{-1}$. Both systems exhibit a high cycling stability, with retention of 94.4 and 91.1\% initial capacitance after 2000 cycles. This indicates that the addition of $\mathrm{K}_{3} \mathrm{Fe}(\mathrm{CN})_{6}$ into $\mathrm{KOH}$ electrolyte does not affect the stability of the electrode material. In addition, the system can be charged quickly, and discharged slowly, which means that the promise can be offered to realize a high-performance battery-type supercapacitor.

Although the cost is relatively high, $\mathrm{Ru} / / \mathrm{Ru}$ symmetric supercapacitor shows large specific capacitance, high potential window, and excellent cycling stability. For example, Xia et al. (2014) have developed $1.8 \mathrm{~V}$ symmetric supercapacitor using nanocrystalline $\mathrm{Ru}$ films as both negative and positive electrodes. The $\mathrm{Ru} / / \mathrm{Ru}$ symmetric supercapacitor exhibits a large areal 
TABLE 2 | Electrochemical performance of the asymmetric supercapacitors based on conventional electrode materials

\begin{tabular}{|c|c|c|c|c|c|c|c|}
\hline Electrode & Electrolyte & $\begin{array}{l}\text { Capacitance } \\
\left(\mathrm{F} \mathrm{g}^{-1}\right)\end{array}$ & $\begin{array}{c}\text { Potential } \\
\text { window (V) }\end{array}$ & $\begin{array}{l}\text { Energy density } \\
\left(\mathrm{Wh} \mathrm{kg}^{-1}\right)\end{array}$ & $\begin{array}{l}\text { Power density } \\
\left(\mathbf{k W ~ k g}^{-1}\right)\end{array}$ & Stability & Reference \\
\hline $\mathrm{NaMnO}_{2} / / \mathrm{AC}$ & $\mathrm{Na}_{2} \mathrm{SO}_{4}$ & 38.9 & 1.9 & 19.5 & 0.13 & $97 \%$ (10,000 cp) & Qu et al. (2009) \\
\hline $\mathrm{K}_{0.27} \mathrm{MnO}_{2} / / \mathrm{AC}$ & $\mathrm{K}_{2} \mathrm{SO} 4$ & 57.7 & 1.8 & 25.3 & 0.14 & $98 \%(10,000 \mathrm{cp})$ & Qu et al. (2010) \\
\hline $\mathrm{NiO} / / \mathrm{AC}$ & $\mathrm{KOH}$ & 38 & 1.5 & - & - & $50 \%$ (1000 cp) & Wang et al. (2008) \\
\hline $\mathrm{MnO}_{2}-\mathrm{AC} / / \mathrm{AC}$ & $\mathrm{Na}_{2} \mathrm{SO}_{4}$ & 33.2 & 2.0 & 18.2 & 10.1 & $92 \%(2500$ cp) & Gao et al. (2011) \\
\hline
\end{tabular}

TABLE 3 | Electrochemical performance of the asymmetric supercapacitors based on new electrode materials

\begin{tabular}{|c|c|c|c|c|c|c|c|}
\hline Electrode & Electrolyte & $\begin{array}{l}\text { Capacitance } \\
\left(\mathbf{F ~ g}^{-1}\right)\end{array}$ & $\begin{array}{c}\text { Potential } \\
\text { window (V) }\end{array}$ & $\begin{array}{l}\text { Energy density } \\
\left(\mathrm{Wh} \mathrm{kg}^{-1}\right)\end{array}$ & $\begin{array}{l}\text { Power density } \\
\quad\left(\mathbf{k W ~ k g}^{-1}\right)\end{array}$ & Stability & Reference \\
\hline $\mathrm{rGO} / / \mathrm{MnO}_{2}-\mathrm{rGO}$ & $\mathrm{Na}_{2} \mathrm{SO}_{4}$ & 59.9 & 1.6 & 21.2 & 0.82 & 89.4\% (1000cp) & Wu et al. (2014) \\
\hline $\mathrm{MnO}_{2}-\mathrm{NF} / / \mathrm{G}$ & $\mathrm{Na}_{2} \mathrm{SO}_{4}$ & - & - & 30.2 & 14.5 & $83.4 \%$ (5000ср) & Gao et al. (2012) \\
\hline $\begin{array}{l}\mathrm{NiCO}_{2} \mathrm{O}_{4}-\mathrm{Co}_{0.33} \mathrm{Ni}_{0.67} \\
(\mathrm{OH})_{2} / / \mathrm{CMK}-3\end{array}$ & $\mathrm{KOH}$ & 87.9 & 1.6 & 31.2 & 396 & $82 \%$ (3000 cp) & Xu et al. (2014) \\
\hline $\mathrm{MnO}_{2}-\mathrm{NPG} / / \mathrm{PPy}-\mathrm{NPG}$ & $\mathrm{LiClO}_{4}$ & 193 & 1.8 & 86 & 25 & 85\% (2000 cp) & Hou et al. (2014) \\
\hline $\mathrm{Co}(\mathrm{OH})_{2} / \mathrm{NN}$ & $\mathrm{KOH}$ & 62.4 & 1.6 & 22 & 19.5 & $80 \%$ (4000 cp) & Wang et al. (2014a) \\
\hline NiO-GF//HPNCNTS & $\mathrm{KOH}$ & 116 & 1.4 & 32 & 0.7 & $94 \%$ (2000 cp) & Wang et al. (2014b) \\
\hline CoO-PPy//AC & $\mathrm{NaOH}$ & - & 1.6 & 43.5 & 5.5 & $91.5 \%(20,000$ cp) & Zhou et al., 2013 \\
\hline $\mathrm{NiCO}_{2} \mathrm{O}_{4}-\mathrm{rGO} / \mathrm{AC}$ & $\mathrm{KOH}$ & 99.4 & 1.3 & 23.3 & 0.32 & $93 \%$ (2500ср) & Wang et al. (2012c) \\
\hline
\end{tabular}

capacitance $\left(68 \mathrm{mF} \mathrm{cm}^{-2}\right)$, high cycling stability (no capacitance loss after 2000 charge-discharge cycles), and good rate capability. Similarly, a novel symmetric $\mathrm{RuO}_{2} / \mathrm{RuO}_{2}$ supercapacitor with a high-operating voltage of $1.6 \mathrm{~V}$ is also built using the nanocrystalline hydrous $\mathrm{RuO}_{2}$ electrode, exhibiting an energy density of 18.77 $\mathrm{Wh} \mathrm{kg}^{-1}$ at a power density of $500 \mathrm{~W} \mathrm{~kg}^{-1}$ (Xia et al., 2012).

For other inexpensive transition-metal oxides symmetric capacitors, working potential window are relatively low (no more than $1 \mathrm{~V}$ ), leading to relatively low-energy density. The researchers try to improve working potential window for the cheap metal oxides symmetric supercapacitor, but the effect is not obvious. For example, Reddy et al. (2009) have synthesized $\mathrm{Au}-\mathrm{MnO}_{2} / \mathrm{CNT}$ hybrid coaxial nanotube arrays and prepared $\mathrm{MnO}_{2} / / \mathrm{MnO}_{2}$ symmetric capacitor. CNTs serve as an additive for improving the electrical conductivity of the manganese oxide, leading high-specific capacitance, power density, and cycling stability; however, the potential window is only $0.7 \mathrm{~V}$. Lu et al. (2012) have synthesized nickel-cobalt oxide (NCO) nanosheets on FTO substrates and prepared a symmetric supercapacitor based on two NCO electrodes, exhibiting a high-specific capacitance of $89.2 \mathrm{Fg}^{-1}$ at $0.17 \mathrm{Ag}^{-1}$, but a low-potential window of $0.5 \mathrm{~V}$.

\section{Asymmetric Supercapacitors}

As an improvement to symmetric supercapacitors, asymmetric supercapacitors combining electric double-layer anode (carbon materials) and redox reaction cathode (such as metal hydroxide/oxide materials, Li-ion battery materials, composite electrode material) show promising capability to enhance the energy density, that is because asymmetric supercapacitors can make full use of the different potential windows of the two electrodes to increase the operation voltage and enhanced specific capacitance in the cell system. More recently, to obtain higher energy density, considerable research efforts have been devoted to the various of asymmetric capacitor systems, mainly including $\mathrm{AC} / / \mathrm{LiMn}_{2} \mathrm{O}_{4}$
(Qu et al., 2009, 2010), AC//NiO (Wang et al., 2008), AC// $\mathrm{MnO}_{2}$ (Gao et al., 2010), and so on. Table 2 summarizes the electrochemical performances of these conventional asymmetric supercapacitors. For these asymmetric supercapacitors, AC is commonly used as a typical negative electrode material, metal oxides are employed as the positive electrode material. The poor specific capacitance of AC and low stability of metal oxides/hydroxides would also greatly restrict the supercapacitor performance, resulting relatively low-energy density $\left(10 \sim 30 \mathrm{Wh} \mathrm{kg}^{-1}\right)$, power density, and cycling stability. Recently, partially due to the discovery of new electrode materials and new synthesis method, advanced supercapacitors with high performance have been developed. As shown in Table 3, asymmetric supercapacitors with high-performance electrode materials as cathode and anode materials show significant superiority in energy density $\left(\sim 90 \mathrm{Wh} \mathrm{kg}^{-1}\right)$, power density, and cycling stability.

\section{Trends in ES}

Electrochemical capacitors with high-power density and cycling performance have bridged the gap between conventional capacitors and batteries. However, one of the key challenges for ES is the limited energy density. To overcome this challenge, ECs research should focus on improving the specific capacitance and widen potential window.

(1) Improve the specific capacitance. One common strategy is to design and synthesis new materials, which must satisfy the following conditions: first, good conductivity for efficient charge transport; second, high-specific surface area for more active sites; third, good mechanical and electrochemical stability for good cycling performance; last, favorable pores-ize distribution for high-rate ions diffusion. The ECs electrode material exploration directions are composite materials and nanomaterials, with coating active materials with conductive 
carbon or constructing a novel hybrid metal oxide nanostructure electrode for ECs. Nanocomposite can realize synergistic effect, facilitating electron and proton conduction, enhancing specific surface area, expanding active sites, inducing porosity, protecting active materials from mechanical degradation, improving cycling stability. Another effective one is to pursue new electrolyte with high-electrochemical activity and reversibility, contributing additional pseudocapacitance in specific potential window, and the problem of electrochemical stability for the composite electrode system should to be paid more attention further.

(2) Widen the potential window. The strategy of developing and matching asymmetric capacitors can make use of the different potential windows of the two electrodes to increase the operation voltage in the cell system. However, the matching problem appears between positive and negative electrode. If the electrodes are matched well, the overall performance of the supercapacitor will be improved. Otherwise, its performance may drop or the supercapacitor may be damaged.

Solid-state supercapacitors (SSCs) are emerging as energystorage devices due to excellent stability, light weight, and easy to handle, however, suffer from poor rate capability due to limited

\section{References}

An, K. H., Kim, W. S., Park, Y. S., Choi, Y. C., Lee, S. M., Chung, D. C., et al. (2001). Supercapacitors using single walled carbon nanotube electrodes. Adv. Mater. 13, 497-500. doi:10.1002/1521-4095(200104)13:7<497::AID-ADMA497>3.0. $\mathrm{CO} ; 2-\mathrm{H}$

Anantharamulu, N., Rao, K. K., Rambabu, G., Kumar, B. V., Radha, V., and Vithal, M. (2011). A wide-ranging review on Nasicon type materials. J. Mater. Sci. 46, 2821-2837. doi:10.1007/s10853-011-5302-5

Asano, Y., Komatsu, T., Murashiro, K., and Hoshino, K. (2011). Capacitance studies of cobalt compound nanowires prepared via electrodeposition. J. Power Sources 196, 5215-5222. doi:10.1016/j.jpowsour.2011.01.101

Burke, A. (2000). Ultracapacitors: why, how, and where is the technology. J. Power Sources 91, 37-50. doi:10.1016/S0378-7753(00)00485-7

Burke, A. (2010). Ultracapacitor technologies and application in hybrid and electric vehicles. Int. J. Energ. Res. 34, 133-151. doi:10.1002/er.1654

Cao, C. Y., Guo, W., Cui, Z. M., Song, W. G., and Cai, W. (2011). Microwave assisted gas/liquid interfacial synthesis of flowerlike $\mathrm{NiO}$ hollow nanosphere precursors and their application as supercapacitor electrodes. J. Mater. Chem. 21, 3204-3209. doi:10.1039/C0JM03749D

Chang, J. K., Wu, C. M., and Sun, I. W. (2010). Nano-architectured $\mathrm{Co}(\mathrm{OH})_{2}$ electrodes constructed using an easily-manipulated electrochemical protocol for high-performance energy storage applications. J. Mater. Chem. 20, 3729-3735. doi:10.1039/b925176f

Chen, L. F., Huang, Z. H., Liang, H. W., Yao, W. T., Yu, Z. Y., and Yu, S. H. (2013a). Flexible all-solid-state high-power supercapacitor fabricated with nitrogen-doped carbon nanofiber electrodematerial derived from bacterial cellulose. Energ. Environ. Sci. 6, 3331-3338. doi:10.1039/ C3EE42366B

Chen, W., Rakhi, R. B., and Alshareef, H. N. (2013b). Capacitance enhancement of polyaniline coated curved-graphene supercapacitors in a redox-active electrolyte. Nanoscale 5, 4134-4138. doi:10.1039/c3nr00773a

Chen, S., Zhu, J., and Wang, X. (2010). One-step synthesis of graphene-cobalt hydroxide nanocomposites and their electrochemical properties. J. Phys. Chem. C 114, 11829-11834. doi:10.1021/jp1048474

Conte, M. (2010). Supercapacitors technical requirements for new applications. Fuel Cell 10, 806-818. doi:10.1002/fuce.201000087 ion-diffusion rate in solid-state electrolytes, large resistance of the electrode material. Asymmetric capacitors with redox electrolyte can exhibits large specific capacitance and wide potential window, resulting in an enhanced energy density. The supercapacitor can be regarded as a novel hybrid supercapacitor application that combines two energy-storage processes: the double-layer capacitance or faradaic pseudocapacitance characteristic from electrode materials and the faradaic pseudocapacitance from electrolyte. It is important to design high-performance electrode materials, choose the suitable electrolyte, solve well matching problem. With the high resistance and low charge-discharge stability resolved, such asymmetric supercapacitor is expected to be a highly promising candidate for application in high-performance energy-storage systems.

\section{Acknowledgments}

The support from National Natural Science Foundation of China (Grant Nos. 50525204 and 50832001), the special Ph.D. program (Grant No. 200801830025) from MOE, Major science and technology project of Jilin Province (Grant No. 11ZDGG010), NSF of China (grant no. 51372095), program for Changjiang Scholars and Innovative Research Team in University, the "211" and "985" project of Jilin University, China, is highly appreciated.

Conway, B. E. (1999). Electrochemical Supercapacitors: Scientific Fundamentals and Technological Applications. New York, NY: Kluwer Academic Publishers, Plenum Press.

Diaz, R., Orcajo, M. G., Botas, J. A., Calleja, G., and Palma, J. (2012). Co8-MOF-5 as electrode for supercapacitors. Mater. Lett. 68, 126-128. doi:10.1016/j.matlet. 2011.10 .046

Fan, L. Z., Hu, Y. S., Maier, J., Adelhelm, P., Smarsly, B., and Antonietti, M. (2007) High electroactivity of polyaniline in supercapacitors by using a hierarchically porous carbon monolith as a support. Adv. Funct. Mater. 17, 3083-3087. doi:10. 1002/adfm.200700518

Fang, Q. L., Evans, D. A., Roberson, S. L., and Zheng, J. P. (2001). Ruthenium oxide film electrodes prepared at low temperatures for electrochemical capacitors. J. Electrochem. Soc. 148, A833-A837. doi:10.1149/1.1379739

Frackowiak, E. (2007). Carbon materials for supercapacitor application. Phys. Chem. Chem. Phys. 9, 1774-1785. doi:10.1039/B618139M

Frackowiak, E., and Beguin, F. (2001). Carbon materials for the electrochemical storage of energy in capacitors. Carbon N. Y. 39, 937-950. doi:10.1016/ S0008-6223(00)00183-4

Gao, H., Xiao, F., Ching, C. B., and Duan, H. (2012). High-performance asymmetric supercapacitor based on graphene hydrogel and nanostructured $\mathrm{MnO}_{2}$. ACS Appl. Mater. Interfaces 4, 2801-2810. doi:10.1021/am300455d

Gao, P. C., Lu, A. H., and Li, W. C. (2011). Dual functions of activated carbon in a positive electrode for $\mathrm{MnO}_{2}$-based hybrid supercapacitor. J. Power Sources 196, 4095-4101. doi:10.1016/j.jpowsour.2010.12.056

Gao, Y., Chen, S., Cao, D., Wang, G., and Yin, J. (2010). Electrochemical capacitance of $\mathrm{Co}_{3} \mathrm{O}_{4}$ nanowire arrays supported on nickel foam. J. Power Sources 195, 1757-1760. doi:10.1016/j.jpowsour.2009.09.048

Hou, Y., Chen, L., Liu, P., Kang, J., Fujita, T., and Chen, M. (2014). Nanoporousmetal based flexible asymmetric pseudocapacitors. J. Mater. Chem. A2, 10910-10916. doi:10.1039/c4ta00969j

Hu, C. C., Chang, K. H., Lin, M. C., and Wu, Y. T. (2006). Design and tailoring of the nanotubular arrayed architecture of hydrous $\mathrm{RuO}_{2}$ for next generation supercapacitors. Nano Lett. 6, 2690-2695. doi:10.1021/nl061576a

$\mathrm{Hu}$, C. C., and Huang, Y. H. (2001). Effects of preparation variables on the deposition rate and physicochemical properties of hydrous ruthenium oxide for electrochemical capacitors. Electrochim. Acta 46, 3431-3444. doi:10.1016/ S00134686(01)00543-6 
Huang, S., Zhu, G. N., Zhang, C., Tjiu, W. W., Xia, Y. Y., and Liu, T. (2012). Immobilization of Co-Al layered double hydroxides on graphene oxide nanosheets: growth mechanism and supercapacitor studies. ACS Appl. Mater. Interfaces 4, 2242-2249. doi:10.1021/am300247x

Inagaki, M., Konno, H., and Tanaike, O. (2010). Carbon materials for electrochemical capacitors. J. Power Sources 195, 7880-7903. doi:10.1016/j. jpowsour.2010.06.036

Jeong, Y. U., and Manthiram, A. (2001). Amorphous tungsten oxide/ruthenium oxide composites for electrochemical capacitors. J. Electrochem. Soc. 148, A189-A193. doi:10.1002/chin.200129012

Jia, Q. X., Song, S. G., Wu, X. D., Cho, J. H., Foltyn, S. R., Findikoglu, A. T., et al. (1996). Epitaxial growth of highly conductive $\mathrm{RuO}_{2}$ thin films on (100) Si. Appl. Phys. Lett. 68, 1069-1071. doi:10.1063/1.115715

Jiang, H., Zhao, T., Li, C., and Ma, J. (2011). Hierarchical self-assembly of ultrathin nickel hydroxide nanoflakes for high-performance supercapacitors. J. Mater. Chem. 21, 3818-3823. doi:10.1039/C0JM03830J

Ke, Y. F., Tsai, D. S., and Huang, Y. S. (2005). Electrochemical capacitors of $\mathrm{RuO}_{2}$ nanophase grown on LiNbO3 (100) and sapphire (0001) substrates. J. Mater. Chem. 15, 2122-2127. doi:10.1039/B502754C

Khazaei, M., Arai, M., Sasaki, T., Chung, C. Y., Venkataramanan, N. S., Estili, M., et al. (2012). Novel electronic and magnetic properties of two-dimensional transition metal carbides and nitrides. Adv. Funct. Mater. 23, 2185-2192. doi:10. 1002/adfm.201202502

Kim, I. H., and Kim, K. B. (2006). Electrochemical characterization of hydrous ruthenium oxide thin-film electrodes for electrochemical capacitor applications. J. Electrochem. Soc. 153, A383-A389. doi:10.1149/1.2147406

Kurtoglu, M., Naguib, M., Gogotsi, Y., and Barsoum, M. W. (2012). First principles study of two-dimensional early transition metal carbides. MRS Commun. 2, 133-137. doi:10.1557/mrc.2012.25

Le, L. T., Ervin, M. H., Qiu, H., Fuchs, B. E., and Lee, W. Y. (2011). Graphene supercapacitor electrodes fabricated by inkjet printing and thermal reduction of graphene oxide. Electrochem. commun. 13, 355-358. doi:10.1016/j.elecom.2011. 01.023

Lee, H., Cho, M. S., Kim, I. H., Nam, J. D., and Lee, Y. (2010). RuOx/polypyrrole nanocomposite electrode for electrochemical capacitors. Synth. Met. 160, 1055-1059. doi:10.1016/j.synthmet.2010.02.026

Lee, J. W., Hall, A. S., Kim, J. D., and Mallouk, T. E. (2012a). A facile and templatefree hydrothermal synthesis of $\mathrm{Mn}_{3} \mathrm{O}_{4}$ nanorods on graphene sheets for supercapacitor electrodes with long cycle stability. Chem. Mater. 24, 1158-1164. doi: $10.1021 / \mathrm{cm} 203697$

Lee, K. K., Deng, S., Fan, H. M., Mhaisalkar, S., Tan, H. R., Tok, E. S., et al. (2012b). a- $\mathrm{Fe}_{2} \mathrm{O}_{3}$ nanotubes-reduced graphene oxide composites as synergistic electrochemical capacitor materials. Nanoscale 4, 2958-2961. doi:10.1039/ c2nr11902a

Lee, D. Y., Yoon, S. J., Shrestha, N. K., Lee, S. H., Ahn, H., and Han, S. H. (2012c). Unusual energy storage and charge retention in co-based metalorganic-frameworks. Microporous Mesoporous Mater. 153, 163-165. doi:10. 1016/j.micromeso.2011.12.040

Lee, S. H., Lee, H., Cho, M. S., Nam, J. D., and Lee, Y. (2013). Morphology and composition control of manganese oxide by the pulse reverse electrodeposition technique for high performance supercapacitors. J. Mater. Chem. A 1, 14606-14611. doi:10.1039/C3TA12828H

Liu, C. G., Yu, Z. N., Neff, D., Zhamu, A., and Jang, B. Z. (2010). Graphene-based supercapacitor with an ultrahigh energy density. Nano Lett. 10, 4863-4868. doi:10.1021/nl102661q

Liu, J., Jiang, J., Cheng, C., Li, H., Zhang, J., Gong, H., et al. (2011). $\mathrm{Co}_{3} \mathrm{O}_{4}$ Nanowire@ $\mathrm{MnO}_{2}$ ultrathin nanosheet core/shell arrays: a new class of highperformance pseudocapacitive materials. Adv. Mater. 23, 2076-2081. doi:10. 1002/adma.201100058

Lu, X., Huang, X., Xie, S., Zhai, T., Wang, C., Zhang, P., et al. (2012). Controllable synthesis of porous nickel-cobalt oxide nanosheets for supercapacitors. J. Mater. Chem. 22, 13357-13364. doi:10.1039/C2JM30927K

Lukatskaya, M. R., Mashtalir, O., Ren, C. E., Dall'Agnese, Y., Rozier, P., Taberna, P. L., et al. (2013). Cation intercalation and high volumetric capacitance of two-dimensional titaniumcarbide. Science 341, 1502-1504. doi:10.1126/science. 1241488

Obradovic, M. D., Tripkovic, A. V., and Gojkovic, S. L. (2009). The origin of high activity of Pt-Au surfaces in the formic acid oxidation. Electrochim. Acta 55, 204-209. doi:10.1016/j.electacta.2009.08.038
Pandolfo, A. G., and Hollenkamp, A. F. (2006). Carbon properties and their role in supercapacitors. J. Power Sources 157, 11-27. doi:10.1016/j.jpowsour.2006.02. 065

Pognon, G., Cougnon, C., Mayilukila, D., and Bélanger, D. (2012). Catechol modified activated carbon prepared by the diazonium chemistry for application as active electrode material in electrochemical capacitor. ACS Appl. Mater. Interfaces 4, 3788-3796. doi:10.1021/am301284n

Qu, Q., Li, L., Tian, S., Guo, W., Wu, Y., and Holze, R. (2010). A cheap asymmetric supercapacitor with high energy at high power: activated carbon $/ / \mathrm{K}_{0.27} \mathrm{MnO}_{2} \cdot 0.6 \mathrm{H}_{2} \mathrm{O}$. J. Power Sources 195, 2789-2794. doi:10.1016/j.jpowsour.2009.10.108

Qu, Q. T., Shi, Y., Tian, S., Chen, Y. H., Wu, Y. P., and Holze, R. (2009). A new cheap asymmetric aqueous supercapacitor: activated carbon $/ / \mathrm{NaMnO}_{2}$. J. Power Sources 194, 1222-1225. doi:10.1016/j.jpowsour.2009.06.068

Ragupathy, P., Park, D. H., Campet, G., Vasan, H. N., Hwang, S. J., Choy, J. H., et al. (2009). Remarkable capacity retention of nanostructured manganese oxide upon cycling as an electrode material for supercapacitor. J. Phys. Chem. C 113, 6303-6309. doi:10.1021/jp811407q

Reddy, A. L. M., Shaijumon, M. M., Gowda, S. R., and Ajayan, P. M. (2009). Multisegmented $\mathrm{Au}-\mathrm{MnO}_{2}$ /carbon nanotube hybrid coaxial arrays for highpower supercapacitor applications. J. Phys. Chem. C 114, 658-663. doi:10.1021/ jp908739q

Ricketts, B. W., and Ton-That, C. (2000). Self-discharge of carbon-based supercapacitors with organic electrolytes. J. Power Sources 89, 64-69. doi:10.1016/ S03787753(00)00387-6

Roldán, S., Granda, M., Menéndez, R., Santamaría, R., and Blanco, C. (2011). Mechanisms of energy storage in carbon-based supercapacitors modified with a quinoid redox-active electrolyte. J. Phys. Chem. C 115, 17606-17611. doi:10. 1021/jp205100v

Sakiyama, K., Onishi, S., Ishihara, K., Orita, K., Kijiyama, T., Hosoda, N., et al. (1993). Deposition and properties of reactively sputtered ruthenium dioxide films. J. Electrochem. Soc. 140, 834-839. doi:10.1002/chin.199328038

Saliger, R., Fischer, U., Herta, C., and Fricke, J. (1998). High surface area carbon aerogels for supercapacitors. J. Non Cryst. Solids 225, 81-85. doi:10.1016/ S00223093(98)00104-5

Sellam, A., and Hashmi, S. A. (2013). High rate performance of flexible pseudocapacitors fabricated using ionic-liquid-based proton conducting polymer electrolyte with poly(3, 4-ethylenedioxythiophene):poly(styrene sulfonate) and its hydrous rutheniumoxide composite electrodes. ACS Appl. Mater. Interfaces 5, 3875-3883. doi:10.1021/am4005557

Senthilkumar, S. T., Selvan, R. K., Lee, Y. S., and Melo, J. S. (2013). Electric double layer capacitor and its improved specific capacitance using redox additive electrolyte. J. Mater. Chem. A 1, 1086-1095. doi:10.1039/c2ta00210h

Sharma, P., and Bhatti, T. S. (2010). A review on electrochemical double-layer capacitors. Energ. Convers. Manag. 51, 2901-2912. doi:10.1016/j.enconman. 2010.06.031

Si, W. P., Yan, C. L., Chen, Y., Oswald, S., Han, L. Y., and Schmidt, O. G. (2013). On chip, all solid-state and flexible micro-supercapacitors with high performance based on MnOx/Au multilayers. Energ. Environ. Sci. 6, 3218-3223. doi:10.1039/ C3EE41286E

Simon, P., and Burke, A. (2008). Nanostructured carbons: double-layer capacitance and more. Electrochem. Soc. Interface 17, 38-43.

Simon, P., and Gogotsi, Y. (2008). Materials for electrochemical capacitors. Nat. Mater. 7, 845-854. doi:10.1038/nmat2297

Song, M. K., Cheng, S., Chen, H., Qin, W., Nam, K. W., Xu, S., et al. (2012). Anomalous pseudocapacitive behavior of a nanostructured, mixed-valent manganese oxide film for electrical energy storage. Nano Lett. 12, 3483-3490. doi:10.1021/ nl300984y

Song, X., and Gao, L. (2008). Facile synthesis and hierarchical assembly of hollow nickel oxide architectures bearing enhanced photocatalytic properties. J. Phys. Chem. C 112, 15299-15305. doi:10.1021/jp804921g

Stoller, M. D., Park, S., Zhu, Y., An, J., and Ruoff, R. S. (2008). Graphene-based ultracapacitors. Nano Lett. 8, 3498-3502. doi:10.1021/nl802558y

Su, L. H., Zhang, X. G., Mi, C. H., Gao, B., and Liu, Y. (2009). Improvement of the capacitive performances for Co-Al layered double hydroxide by adding hexacyanoferrate into the electrolyte. Phys. Chem. Chem. Phys. 11, 2195-2202. doi:10.1039/b814844a

Tao, J., Liu, N., Li, L., Su, J., and Gao, Y. (2014). Hierarchical nanostructures of polypyrrole@ $\mathrm{MnO}_{2}$ composite electrodes for high performance 
solid-state asymmetric supercapacitors. Nanoscale 6, 2922-2928. doi:10.1039/ C3NR05845J

Wang, D. W., Li, F., and Cheng, H. M. (2008). Hierarchical porous nickel oxide and carbon as electrode materials for asymmetric supercapacitor. J. Power Sources 185, 1563-1568. doi:10.1016/j.jpowsour.2008.08.032

Wang, G., Shen, X., Horvat, J., Wang, B., Liu, H., Wexler, D., et al. (2009). Hydrothermal synthesis and optical, magnetic, and supercapacitance properties of nanoporous cobalt oxide nanorods. J. Phys. Chem. C 113, 4357-4361. doi:10. 1021/jp8106149

Wang, H. Q., Yang, G., Li, Q. Y., Zhong, X. X., Wang, F. P., Li, Z. S., et al. (2011). Porous nano- $\mathrm{MnO}_{2}$ : large scale synthesis via a facile quick-redox procedure and application in a supercapacitor. New J. Chem. 35, 469-475. doi:10.1039/ C0NJ00712A

Wang, R., Yan, X., Lang, J., Zheng, Z., and Zhang, P. (2014a). A hybrid supercapacitor based on flower-like $\mathrm{Co}(\mathrm{OH})_{2}$ and urchin-like VN electrode materials. J. Mater. Chem. A 2, 12724-12732. doi:10.1039/c4ta01296h

Wang, H., Yi, H., Chen, X., and Wang, X. (2014b). Asymmetric supercapacitors based on nano-architectured nickel oxide/graphene foam and hierarchical porous nitrogen-doped carbon nanotubes with ultrahigh-rate performance. J. Mater. Chem. A 2, 3223-3230. doi:10.1039/C3TA15046A

Wang, X., Sumboja, A., Lin, M., Yan, J., and Lee, P. S. (2012a). Enhancing electrochemical reaction sites in nickel-cobalt layered double hydroxides on zinc tin oxide nanowires: a hybrid material for an asymmetric supercapacitor device. Nanoscale 4, 7266-7272. doi:10.1039/c2nr31590d

Wang, X., Wang, Y. Y., Zhao, C. M., Zhao, Y. X., Yan, B. Y., and Zheng, W. T. $(2012 b)$. Electrodeposited $\mathrm{Ni}(\mathrm{OH})_{2}$ nanoflakes on graphite nanosheets prepared by plasma-enhanced chemical vapor deposition for supercapacitor electrode. New J. Chem. 36, 1902-1906. doi:10.1039/C2NJ40308K

Wang, X., Liu, W. S., Lu, X., and Lee, P. S. (2012c). Dodecyl sulfate-induced fast faradic process in nickel cobalt oxide-reduced graphite oxide composite material and its application for asymmetric supercapacitor device. J. Mater. Chem. 22, 23114-23119. doi:10.1039/C2JM35307E

Wang, Y., and Zhang, X. (2004). Preparation and electrochemical capacitance of $\mathrm{RuO}_{2} / \mathrm{TiO}_{2}$ nanotubes composites. Electrochim. Acta 49, 1957-1962. doi:10. 1016/j.electacta.2003.12.023

Wei, Y. Z., Fang, B., Iwasa, S., and Kumagai, M. (2005). A novel electrode material for electric double-layer capacitors. J. Power Sources 141, 386-391. doi:10.1016/ j.jpowsour.2004.10.001

Wu, J. H., Yu, H. J., Fan, L. Q., Luo, G. G., Lin, J. M., and Huang, M. L. (2012). A simple and high-effective electrolyte mediated with p-phenylenediamine for supercapacitor. J. Mater. Chem. 22, 19025-19030. doi:10.1039/C2JM33856D

Wu, S., Chen, W., and Yan, L. (2014). Fabrication of a 3D MnO2/graphene hydrogel for high-performance asymmetric supercapacitors. J. Mater. Chem. A 2, 2765-2772. doi:10.1039/C3TA14387B

Xia, H., Li, B., and Lu, L. (2014). 1.8 V symmetric supercapacitors developed using nanocrystalline Ru films as electrodes. RSC Adv. 4, 11111-11114. doi:10.1039/ C3RA47396A

Xia, H., Meng, Y. S., Yuan, G., Cui, C., and Lu, L. (2012). A symmetric $\mathrm{RuO}_{2} / \mathrm{RuO}_{2}$ supercapacitor operating at $1.6 \mathrm{~V}$ by using a neutral aqueous electrolyte. Electrochem. Solid State Lett. 15, A60-A63. doi:10.1149/2.023204esl

Xia, X. H., Tu, J. P., Wang, X. L., Gu, C. D., and Zhao, X. B. (2011a). Mesoporous $\mathrm{Co}_{3} \mathrm{O}_{4}$ monolayer hollow-sphere array as electrochemical pseudocapacitor material. Chem. Commun. 47, 5786-5788. doi:10.1039/c1cc11281c

Xia, X., Tu, J., Mai, Y., Chen, R., Wang, X., Gu, C., et al. (2011b). Graphene sheet/porous $\mathrm{NiO}$ hybrid film for supercapacitor applications. Chemistry 17, 10898-10905. doi:10.1002/chem.201100727

Xu, J., Gao, L., Cao, J., Wang, W., and Chen, Z. (2010). Preparation and electrochemical capacitance of cobalt oxide $\left(\mathrm{Co}_{3} \mathrm{O}_{4}\right)$ nanotubes as supercapacitor material. Electrochim. Acta 56, 732-736. doi:10.1016/j.electacta.2010.09.092

Xu, K., Zou, R., Li, W., Liu, Q., Liu, X., An, L., et al. (2014). Design and synthesis of 3Dinterconnectedmesoporous $\mathrm{NiCo}_{2} \mathrm{O}_{4} @ \mathrm{CoxNi}_{1-\mathrm{x}}(\mathrm{OH})_{2}$ core-shell nanosheet arrays with large areal capacitance and high rate performance for supercapacitors. J. Mater. Chem. A 2, 10090-10097. doi:10.1039/C4TA01489H

Yan, J., Fan, Z., Wei, T., Qian, W., Zhang, M., and Wei, F. (2010a). Fast and reversible surface redox reaction of graphene- $\mathrm{MnO}_{2}$ composites as supercapacitor electrodes. Carbon N. Y. 48, 3825-3833. doi:10.1016/j.carbon.2010. 06.047

Yan, J., Wei, T., Qiao, W. M., Shao, B., Zhao, Q. K., Zhang, L. J., et al. (2010b). Rapid microwave-assisted synthesis of graphene nanosheet $/ \mathrm{Co}_{3} \mathrm{O}_{4}$ composite for supercapacitors. Electrochim. Acta 55, 6973-6978. doi:10.1016/j.electacta. 2010.06.081

Yu, G., Hu, L., Vosgueritchian, M., Wang, H., Xie, X., McDonough, J. R., et al. (2011a). Solution-processed graphene/ $\mathrm{MnO}_{2}$ nanostructured textiles for highperformance electrochemical capacitors. Nano Lett. 11, 2905-2911. doi:10.1021/ nl2013828

Yu, G., Hu, L., Liu, N., Wang, H., Vosgueritchian, M., Yang, Y., et al. (2011b). Enhancing the supercapacitor performance of graphene/ $\mathrm{MnO}_{2}$ nanostructured electrodes by conductive wrapping. Nano Lett. 11, 4438-4442. doi:10.1021/ nl2026635

Yu, H., Fan, L., Wu, J., Lin, Y., Huang, M., Lin, J., et al. (2012). Redox-active alkaline electrolyte for carbon-based supercapacitor with pseudocapacitive performance and excellent cyclability. RSC $A d v$. 2, 6736-6740. doi:10.1039/ C2RA20503C

Yuan, C., Yang, L., Hou, L., Shen, L., Zhang, X., and David Lou, X. W. (2012). Growth of ultrathin mesoporous $\mathrm{Co}_{3} \mathrm{O}_{4}$ nanosheet arrays on $\mathrm{Ni}$ foam for high-performance electrochemical capacitors. Energ. Environ. Sci. 5, 7883-7887. doi:10.1039/C2EE21745G

Yuan, C., Zhang, X., Hou, L., Shen, L., Li, D., Zhang, F., et al. (2010). Lysine-assisted hydrothermal synthesis of urchin-like ordered arrays of mesoporous $\mathrm{Co}(\mathrm{OH})_{2}$ nanowires and their application in electrochemical capacitors. J. Mater. Chem. 20, 10809-10816. doi:10.1039/C0JM02174A

Yuan, C., Zhang, X., Su, L., Gao, B., and Shen, L. (2009). Facile synthesis and selfassembly of hierarchical porous $\mathrm{NiO}$ nano/micro spherical superstructures for high performance supercapacitors. J. Mater. Chem. 19, 5772-5777. doi:10.1039/ B902221J

Yuan, Y. F., Xia, X. H., Wu, J. B., Yang, J. L., Chen, Y. B., and Guo, S. Y. (2011). Nickel foam-supported porous $\mathrm{Ni}(\mathrm{OH}) 2 / \mathrm{NiOOH}$ composite film as advanced pseudocapacitor material. Electrochim. Acta 56, 2627-2632. doi:10.1016/j.electacta. 2010.12.001

Zhai, Y., Dou, Y., Zhao, D., Fulvio, P. F., Mayes, R. T., and Dai, S. (2011). Carbon materials for chemical capacitive energy storage. Adv. Mater. 23, 4828-4850. doi:10.1002/adma.201100984

Zhang, C., Zhou, H., Yu, X., Shan, D., Ye, T., Huang, Z., et al. (2014). Synthesis of $\mathrm{RuO}_{2}$ decorated quasi graphene nanosheets and their application in supercapacitors. RSC Adv. 4, 11197-11205. doi:10.1039/C3RA47641C

Zhang, L. L., and Zhao, X. S. (2009). Carbon-based materials as supercapacitor electrodes. Chem. Soc. Rev. 38, 2520-2531. doi:10.1039/b813846j

Zhang, S. W., and Chen, G. Z. (2008). Manganese oxide based materials for supercapacitors. Energ. Mater. 3, 186-200. doi:10.1179/174892409X427940

Zhang, X., Shi, W., Zhu, J., Zhao, W., Ma, J., Mhaisalkar, S., et al. (2010). Synthesis of porous $\mathrm{NiO}$ nanocrystals with controllable surface area and their application as supercapacitor electrodes. Nano Res. 3, 643-652. doi:10.1007/ s12274-010-0024-6

Zhang, Y., Feng, H., Wu, X., Wang, L., Zhang, A., Xia, T., et al. (2009a). Progress of electrochemical capacitor electrode materials: a review. J. Hydrogen Energ. 34, 4889-4899. doi:10.1016/j.ijhydene.2009.04.005

Zhang, H., Cao, G., and Yang, Y. (2009b). Carbon nanotube arrays and their composites for electrochemical capacitors and lithium-ion batteries. Energ. Environ. Sci. 2, 932-943. doi:10.1039/b906812k

Zhao, C. M., Wang, X., Wang, S. M., Wang, H. X., Yang, Y. C., and Zheng, W. T. (2013a). Pseudocapacitive properties of cobalt hydroxide electrodeposited on Ni-foam-supported carbon nanomaterial. Mater. Res. Bull. 48, 3189-3195. doi:10.1016/j.materresbull.2013.04.089

Zhao, C. M., Zheng, W. T., Wang, X., Zhang, H. B., Cui, X. Q., and Wang, H. X. (2013b). Ultrahigh capacitive performance from both $\mathrm{Co}(\mathrm{OH})_{2} /$ graphene electrode and $\mathrm{K}_{3} \mathrm{Fe}(\mathrm{CN})_{6}$ electrolyte. Sci. Rep. 3, 2986-2991. doi:10.1038/srep02986

Zhao, D., Guo, X., Gao, Y., and Gao, F. (2012a). An electrochemical capacitor electrode based on porous carbon spheres hybrided with polyaniline and nanoscale ruthenium oxide. ACS Appl. Mater. Interfaces 4, 5583-5589. doi:10. 1021/am301484s

Zhao, C. M., Wang, X., Wang, S. M., Wang, Y. Y., Zhao, Y. X., and Zheng, W. T. (2012b). Synthesis of $\mathrm{Co}(\mathrm{OH}) 2 /$ graphene/Ni foam nano-electrodes with excellent pseudocapacitive behavior and high cycling stability for supercapacitors. Int. J. Hydrogen Energy 37, 11846-11852. doi:10.1016/j. ijhydene.2012.05.138

Zhao, T., Jiang, H., and Ma, J. (2011). Surfactant-assisted electrochemical deposition of a-cobalt hydroxide for supercapacitors. J. Power Sources 196, 860-864. doi:10. 1016/j.jpowsour.2010.06.042 
Zhao, X., Tian, H., Zhu, M., Tian, K., Wang, J. J., Kang, F., et al. (2009a). Carbon nanosheets as the electrode material in supercapacitors. J. Power Sources 194, 1208-1212. doi:10.1016/j.jpowsour.2009.06.004

Zhao, X., Johnston, C., and Grant, P. S. (2009b). A novel hybrid supercapacitorwith a carbon nanotube cathode and an iron oxide/carbon nanotube composite anode. J. Mater. Chem. 19, 8755-8760. doi:10.1039/B909779A

Zheng, J. P., and Jow, T. R. (1996). High energy and high power density electrochemical capacitors. J. Power Sources 62, 155-159. doi:10.1016/S0378-7753(96) 02424-X

Zhi, M., Xiang, C., Li, J., Li, M., and Wu, N. (2013). Nanostructured carbon-metal oxide composite electrodes for supercapacitors: a review. Nanoscale 5, 72-88. doi:10.1039/c2nr32040a

Zhou, C., Zhang, Y., Li, Y., and Liu, J. (2013). Construction of high-capacitance 3D CoO@polypyrrole nanowire array electrode for aqueous asymmetric supercapacitor. Nano Lett. 13, 2078-2085. doi:10.1021/nl400378j

Zhu, X., Dai, H., Hu, J., Ding, L., and Jiang, L. (2012). Reduced graphene oxide-nickel oxide composite as high performance electrode materials for supercapacitors. J. Power Sources 203, 243-249. doi:10.1016/j.jpowsour. 2011.11.055

Zhu, Y., Murali, S., Stoller, M. D., Velamakanni, A., Piner, R. D., and Ruoff, R. S. (2010). Microwave assisted exfoliation and reduction of graphite oxide for ultracapacitors. Carbon N. Y. 48, 2118-2122. doi:10.1016/j.carbon. 2010.02.001

Conflict of Interest Statement: The authors declare that the research was conducted in the absence of any commercial or financial relationships that could be construed as a potential conflict of interest.

Copyright (C) 2015 Zhao and Zheng. This is an open-access article distributed under the terms of the Creative Commons Attribution License (CC BY). The use, distribution or reproduction in other forums is permitted, provided the original author(s) or licensor are credited and that the original publication in this journal is cited, in accordance with accepted academic practice. No use, distribution or reproduction is permitted which does not comply with these terms. 